\title{
LA SEGURIDAD PÚBLICA EN LA CONSTITUCIÓN POLÍTICA DE LOS ESTADOS UNIDOS MEXICANOS
}

\author{
Susana MARTÍNEZ NAVA*
}

\begin{abstract}
Sumario:
I. Introducción II. La Seguridad en la Constitución III. Sistema Nacional de Seguridad Pública IV. Conclusiones V. Bibliografía.
\end{abstract}

\begin{abstract}
Resumen. Se analizan las disposiciones constitucionales y legales relativas a la seguridad pública, las reformas que labran un concepto de seguridad más acorde con los derechos humanos, en contraste con las características que en este momento son materia de debate y crítica por la forma en la que el Estado mexicano conduce las políticas públicas y que redundan en contextos de mayor violencia. Se contrastan dos discursos, el de los derechos humanos y el de su retroceso, el cual va de la mano con las acciones gubernativas que no han podido ofrecer soluciones al grave problema de inseguridad.
\end{abstract}

Abstract. The present work consists in an analysis of the constitutional and legal dispositions related to public security, the reforms that elaborate a concept of security a bit more in agreement with the human rights, in contrast with the characteristics that at the moment are subject of debate and criticism by the way in which the Mexican State conducts public policies and that result in contexts of greater violence. Two discourses are contrasted, one on human rights and one on the other, which goes hand in hand with governmental actions that have not been able to offer solutions to the serious problem of insecurity.

Palabras clave. Seguridad pública, Constitución, reformas, derechos humanos, políticas públicas.

Key words. Public security, Constitution, reforms, human rights, public policies.

\section{Introducción}

La Constitución Política de los Estados Unidos Mexicanos como documento rector de la vida jurídica nacional, a más de cien años de su promulgación, ha sido múltiplemente reformada. En muchos casos las reformas han sido estructurales, de gran calado en la vida jurídica y política nacional, tal es el caso de las reformas del 18 de junio de 2008 , a la que se le denominó la reforma constitucional en materia de justicia penal y seguridad pública $a^{1}$, así como la del 10 de junio

\footnotetext{
* Maestra en Juicios Orales por la Universidad Autónoma de Durango, candidata a obtener el grado de Doctor por el Doctorado Interinstitucional en Derecho en la línea de investigación de Política Criminal. Docente a nivel superior en la Universidad Interamericana para el Desarrollo sede Fresnillo.

1 En la exposición de motivos de esta reforma se reconoce que:

[...] uno de los problemas más graves en México es la inseguridad en sus dos vertientes tanto física como jurídica, la primera por los altos índices de violencia que se suceden a diario y que afecta a todos los estratos sociales, la segunda por la ausencia de un marco jurídico que contribuya a combatir los altos índices de impunidad.
} 
de 2011 en materia de derechos humanos, que incluso trajo como consecuencia que se inaugurara una nueva época en la jurisprudencia de la Suprema Corte de Justicia de la Nación. En ocasión de esta reforma se argumentó que los compromisos internacionales adquiridos por México frente al contexto de los derechos humanos, hacían necesaria la reforma a la Ley Suprema, a fin de que sus disposiciones estuvieran acordes a éstos y se velara por su reconocimiento y protección ${ }^{2}$.

La vigencia de los derechos humanos son parte esencial de un Estado Constitucional de Derecho como el que pretende ser nuestro país, pues bajo la luz de esta gran reforma a la que se ha hecho mención, no cabe la menor duda de que su instauración consolida el ideal de la democracia como forma de vida en México, sin embargo, una cosa son los postulados de la Constitución y otra es la realidad de este país.

También cabe señalar que la reforma en materia de justicia penal y seguridad pública es el primer intento por introducir algunos elementos indispensables para reforzar la democracia, al menos en la impartición de justicia, sin embargo, existen en dicha reforma muchos elementos que aunque reconocen que la delincuencia es un lastre que aqueja a la sociedad mexicana, recurren a criterios poco compatibles con ese tono democratizador que se pretende usar como bandera ${ }^{3}$.

Hay muchos temas que podrían ser objeto de análisis para tratar de entender la distancia entre el ser y el deber ser, el presente trabajo se refiere a uno, que se ha posicionado como el tema de mayor preocupación por los mexicanos, según la Encuesta Nacional de Victimización y Percepción sobre Seguridad Pública $2016^{4}$, que estima que a nivel nacional el 59.1\% de la población de 18 años y más, considera la inseguridad y delincuencia como el problema más importante que aqueja hoy en día su entidad federativa, seguido del desempleo con $40.8 \%$ y la pobreza con 39.1\%. Así se tiene entonces la necesidad de reflexionar si los postulados constitucionales en materia de seguridad pública se han reformado para ser vigentes conforme a las exigencias de la sociedad actual y desde luego, a los tratados internacionales que México ha suscrito, o bien, dichos postulados son letra muerta, y la norma fundamental ya no responde a las demandas sociales que cada vez son más complejas y acuciantes debido a que la delincuencia, no sólo en

Secretaría de Servicios Parlamentarios (2008), Exposición de motivos de la iniciativa de reforma diversas disposi2

ciones constitucionales en materia de justicia penal y seguridad pública, México, p. 88.

\begin{abstract}
En el proceso evolutivo de los derechos humanos, las naciones han ido creando la normatividad que en el ámbito internacional se requiere para fortalecerlos, como han sido: la Declaración Universal de los Derechos Humanos, el Pacto Internacional de Derechos Civiles y Políticos, el Pacto Internacional de Derechos Económicos, Sociales y Culturales, y la Convención Americana sobre Derechos Humanos, entre otros.

Los anteriores instrumentos jurídicos son los más representativos a escala internacional y han servido como base para el reconocimiento y la protección de los derechos humanos. Estos documentos han sido una de las vías para insertar adecuaciones en el ámbito jurídico de los Estados.

Estas Comisiones Unidas de Puntos Constitucionales y de Derechos Humanos coinciden en el propósito de la minuta del Senado en cuanto a reconocer constitucionalmente los derechos humanos de las personas y establecer las garantías para lograr la efectividad de su protección. Reitera la necesidad de adecuar la Constitución, a fin de incorporar disposiciones en materia de derechos humanos que den cumplimiento a los compromisos internacionales asumidos por el país.
\end{abstract}

Cámara de Diputados (2010), Dictamen de las Comisiones Unidas de Puntos Constitucionales y de Derechos Humanos con proyecto de decreto que modifica la denominación del Capítulo I del Título Primero y reforma artículos 10., 30., 11, 15, 18, 29, 33, 89, 97, 102 y 105 de la Constitución Política de los Estados Unidos Mexicanos. Diario de los Debates, 15 de diciembre de 2010. Discusión y votación, 15 de diciembre de 2010, p. 7, [en línea] disponible en: http://www.diputados.gob.mx/LeyesBiblio/proceso/lxi/117_DOF_1ojun11.pdf

3 Me refiero a la introducción de figuras como el arraigo y el derecho penal del enemigo a nivel constitucional.

${ }^{4}$ Instituto Nacional de Estadística y Geografía (2016), Encuesta Nacional de Victimización y Percepción sobre Seguridad Pública 2016, p. 31, [en línea] disponible en: http://www.beta.inegi.org.mx/contenidos/proyectos/enchogares/ regulares/envipe/2016/doc/envipe2016_presentacion_nacional.pdf 
México, sino en el mundo entero, ha encontrado nuevas formas de manifestarse y tanto los derechos humanos, como el Estado Constitucional de Derecho ven amenazada su existencia.

\section{La Seguridad Pública en la Constitución}

En diversas disposiciones constitucionales aparece la seguridad como una función a cargo del Estado, como una obligación y fin del mismo, así como un derecho a favor de los gobernados, sin embargo en el presente texto se plantea como objetivo analizar la seguridad pública al tomar como base el artículo 21 constitucional, sin pretender limitar a esta norma la noción de seguridad pública, pues ésta encuentra múltiples voces a lo largo del texto constitucional y se relaciona con otros conceptos, tales como la democracia, la soberanía, los derechos humanos, el federalismo, etcétera.

Sin embargo es preciso aclarar que lo que se busca es ubicar a la seguridad pública con los rasgos que la Constitución le ha dado para de ahí derivar consecuencias importantes en la puesta en práctica de esta condición que debe prevalecer para el pleno desarrollo de la vida social.

El artículo 21 constitucional contiene las bases de la seguridad pública en México. Este artículo se divide en cuatro grandes rubros:

La función del Ministerio Público como el investigador de los delitos, la autoridad que ejerce la acción penal, salvo en el caso en que esta sea ejercida por el particular, y los casos en los que, en ejercicio de la acción penal pueda aplicar criterios de oportunidad 5 .

La facultad del Ejecutivo Federal, que con aprobación del Senado, y de acuerdo a un criterio casuístico podrá reconocer la jurisdicción de la Corte Penal Internacional ${ }^{6}$.

La función propia y exclusiva de la autoridad judicial en la imposición, modificación y duración de las penas?.

La función de la seguridad pública a cargo de la federación, las entidades federativas y los municipios.

Esta norma constitucional contempla todos los aspectos generales de la seguridad pública, pues estipula que habrá un órgano encargado de procurar justicia, que con auxilio de la policía,

\footnotetext{
${ }^{5}$ Aunque debe destacarse que si el Ministerio Público ejerce criterios de oportunidad, el ejercicio de la acción penal no tiene razón de ser, sin embargo la redacción del séptimo párrafo del artículo 21 constitucional así lo expresa: El Ministerio Público podrá considerar criterios de oportunidad para el ejercicio de la acción penal, en los supuestos y condiciones que fije la ley.

${ }^{6}$ Lo cual es una flagrante violación al Estatuto de Roma, toda vez que el artículo 120 de este tratado establece que no se admiten reservas y la Convención de Viena (que también es un tratado suscrito por el Estado mexicano) dispone en su artículo $2^{\circ}$ párrafo 1 , inciso d: se entiende por "reserva" una declaración unilateral, cualquiera que sea su enunciado o denominación, hecha por un Estado o por una organización internacional al firmar, ratificar, confirmar formalmente, aceptar o aprobar un tratado o al adherirse a él, con objeto de excluir o modificar los efectos jurídicos de ciertas disposiciones del tratado en su aplicación a ese Estado o a esa organización. Sin embargo a sabiendas de que esta disposición se encontraba en el Estatuto de Roma, el Estado mexicano pretende sustraerse de la jurisdicción de la Corte Penal Internacional conforme a los casos y las condiciones que al Ejecutivo no le convengan o no sea su voluntad hacerlo, pues dependerá de él y de la aprobación del Senado reconocer lo que se supone que ya suscribió, luego el artículo 19 de la Convención de Viena establece: Un Estado o una organización internacional podrá formular una reserva en el momento de firmar, ratificar, confirmar formalmente, aceptar o aprobar un tratado o de adherirse a él, a menos: a) que la reserva esté prohibida por el tratado. Tampoco es válido alegar la prevalencia del derecho interno, pues de acuerdo a la Convención de Viena no puede alegar una contradicción con el derecho interno de cada Estado como pretexto para la inaplicación de un tratado internacional.

7 Desde luego esta disposición se armoniza con el resto de las facultades concedidas por la Constitución al Poder Judicial y como derecho de acceso a la justicia, será previo juicio, conforme a lo dispuesto por el artículo 14 cons-
} 
investigue el delito y, en su caso, ejerza la acción penal; por otra parte contempla que las penas a los responsables de los delitos se aplicarán por parte de uno de los poderes del Estado y que otra dependencia se encargará de prevenir, investigar y perseguir los delitos. Se puede comprender la visión de este esquema en el que es necesario que la sociedad cuente con la función estatal que le permita crear un ambiente de prevención de las conductas que afectan los bienes y derechos de la sociedad, pero en el caso de surjan esas conductas, habrá autoridades facultadas para investigarlas, perseguirlas y aplicarles penas a los sujetos responsables ${ }^{8}$.

Lo que parece ajeno o discordante con el precepto en comento, es la facultad discrecional del ejecutivo para reconocer, con aprobación del Senado, la jurisdicción de la Corte Penal Internacional, toda vez que el Estatuto de Roma tiene como finalidad instituir a la Corte de forma permanente, y facultarla para ejercer su jurisdicción sobre personas respecto de los crímenes más graves de trascendencia internacional, es decir: genocidio, crímenes de lesa humanidad, crímenes de guerra y el crimen de agresión ${ }^{9}$. Se puede leer en este discurso, que se ha llamado discordante líneas arriba, que el Estado mexicano está interesado en preservar la seguridad pública a través de las funciones ejecutiva y judicial, por supuesto, teniendo como base la legislativa, y que será a través de la coordinación de los tres niveles de gobierno, pero ¿cuál es la razón de que no acepte plenamente la jurisdicción de la Corte Penal Internacional?, si el objetivo es proteger a los gobernados de cualquier amenaza a su tranquilidad, ¿un crimen no representa una seria amenaza a la paz social? Quizá en esta parte encontramos una primera incongruencia con el ideal de Estado Constitucional de Derecho que la reforma de 2011 parece dibujar.

Ahora es necesario hacer un análisis de los rasgos que conforman a la seguridad pública para aproximarnos a una comprensión del modelo que la Constitución creó y las posibles razones de su falta de vigencia. Para hacer este análisis tomaremos como eje el artículo 21 y otras normas constitucionales que están en relación con la seguridad pública o con otras instituciones que sean básicas para el análisis, también se hará referencia a las leyes reglamentarias de la materia y a documentos oficiales que se deriven a sus vez de dichas leyes o de la propia Constitución

\section{Definición de la seguridad pública}

La Constitución define a la seguridad pública como una función a cargo de la federación, de los estados y de los municipios. Dicha función, para ser efectiva, comprende la prevención, la investigación y la persecución de los delitos; así como la sanción de las infracciones adminis-

titucional, que ya de por sí establece que corresponde a los tribunales dicha función: Nadie podrá ser privado de la libertad o de sus propiedades, posesiones o derechos, sino mediante juicio seguido ante los tribunales previamente establecidos, en el que se cumplan las formalidades esenciales del procedimiento y conforme a las Leyes expedidas con anterioridad al hecho. Cabe aclarar que el término función tiene una especial acepción conforme al Diccionario Jurídico Mexicano: En el derecho público la noción de facultad se encuentra asociada a la noción de competencia, Competencia material, que se identifica con las facultades del órgano: "El Congreso tiene facultad [...]" (a. 73 de la C), "Son facultades exclusivas de la Cámara [...]." (a. 74 de la C), "Las facultades que no están expresamente concedidas por esta Constitución [...]” (a. 124 de la C). Diccionario jurídico mexicano (1985), Instituto de Investigaciones Jurídicas de la Universidad Nacional Autónoma de México, Tomo IV, México, pp. 176 y 177.

8 Los eslabones de la cadena de seguridad formal: policía, investigación, persecución, juicio y ejecución de penas. García RAmírez, Sergio (2006), "En torno a la seguridad pública. Desarrollo penal y evolución del delito", en: Derechos Humanos. Órgano Informativo de la Comisión de Derechos Humanos del Estado de México, núm. 78, marzo-abril, pp. 41-50, [en linea], disponible en: https://revistas-colaboracion.juridicas.unam.mx/index.php/ derechos-humanos-emx/article/view/24505/21959.

9 Naciones Unidas (2006) Estatuto de Roma de la Corte Penal Internacional, Roma, 1998, Artículo 5. 
trativas contempladas en los reglamentos gubernativos y de policía, que consistirán en multa, arresto o trabajo a favor de la comunidad.

Por su parte, la Ley General del Sistema Nacional de Seguridad Pública la define como:

[...] una función a cargo de la Federación, las entidades federativas y municipios, que tiene como fines salvaguardar la integridad y derechos de las personas, así como preservar las libertades, el orden y la paz públicos y comprende la prevención especial y general de los delitos, la sanción de las infracciones administrativas, así como la investigación y la persecución de los delitos y la reinserción social del sentenciado, en términos de esta Ley, en las respectivas competencias establecidas en la Constitución Política de los Estados Unidos Mexicano ${ }^{10}$.

En la comparación de ambos textos se puede señalar que la Constitución no establece los fines de la seguridad, y que la ley establece fines que adjudica a diversos órganos del Estado de acuerdo al sistema de competencias (mejor dicho, de distribución de facultades) que prevé la Constitución, sin embargo, tampoco en esta última se especifica claramente a qué órganos corresponde la reinserción social del sentenciado ${ }^{11}$.

Por otra parte, la paz pública es una voz que más bien debería cambiarse por paz social, pues el adjetivo pública, es parte esencial del concepto que se pretende definir, pero también su definición entraña la vuelta al concepto seguridad ${ }^{12}$.

La seguridad pública es definida por González Ruiz como el conjunto de políticas y medidas coherentes y articuladas que tienden a garantizar la paz general a través de la prevención y represión de los delitos y las faltas contra el orden público, mediante el sistema de control penal y la policía administrativa ${ }^{13}$.

Hay una gran imprecisión al momento de definir la seguridad pública, tanto en la academia ${ }^{14}$, como en la normatividad, quizá también de ahí derivan las dificultades que presenta el tratamiento del tema, así como las políticas que tienen como objetivo su efectividad.

${ }^{10}$ Artículo $^{\circ}$ de la Ley General del Sistema Nacional de Seguridad Pública, publicada en el Diario Oficial de la Federación el 2 de enero de 2009.

${ }^{11}$ El artículo 18 constitucional sólo establece las bases sobre las cuales se organizará el sistema penitenciario, la separación de hombres y mujeres sentenciadas, así como la operación del sistema en cada orden de gobierno a cargo de instituciones, tribunales y autoridades especializados en la procuración e impartición de justicia para adolescentes.

${ }^{12}$ Del amparo en revisión 4384/2013 tramitado ante la Primera Sala de la Suprema Corte de Justicia de la Nación se desprende la definición de paz pública:

consistente en la legítima expectativa de orden, tranquilidad y seguridad de cada miembro de una comunidad, que representa un fin inherente al Estado y premisa para el goce efectivo de otros derechos. Criterio similar fue adoptado por el tribunal colegiado, al concebir la paz pública como orden y tranquilidad que permitan el equilibrio y armonización de la convivencia entre los habitantes del Distrito Federal.

Asimismo, es importante destacar la paz pública implica una plataforma de convivencia en la cual, no es que desaparezca el conflicto, sino que excluye la violencia como medio para tramitarlo y solucionarlo. Dado lo anterior, la paz pública conlleva para todo individuo el derecho a impedir o denunciar la ejecución de hechos violatorios de derechos humanos y el de estar protegido contra todo acto de arbitrariedad o violencia. Esta definición en realidad se asemeja mucho a la de seguridad en diversas dimensiones.

${ }^{13}$ González Ruiz, Samuel (1994) y otros, Seguridad pública en México: problemas, perspectivas y propuestas. México, UNAM, p. 9.

${ }^{14}$ Un hecho se impone: el análisis de la seguridad carece de un adecuado marco teórico y conceptual interpretativo [...] A diferencia del Derecho Penal o la Criminología, los temas de la seguridad han sido abordados sin elaboraciones teóricas equivalentes a las que dan sustento a tales saberes. Romero RuIz, Guillermo (2008), "El Distrito Federal: entre la seguridad pública y la seguridad ciudadana”, Crimonogénesis, cuatrimestral, año 1, número 2, p. 145. 


\section{Distribución de facultades y competencias}

El sistema de distribución de facultades que priva en México es residual, pues establece que las facultades expresamente concedidas por la Constitución serán en favor de la federación, mientras que las demás serán para las entidades federativas y la ciudad de México ${ }^{15}$. Sin embargo, aun cuando esta fórmula parece sencilla y en efecto es la matriz de la distribución de facultades en el orden jurídico mexicano, en realidad, a lo largo del texto constitucional se encuentran facultades implícitas, concurrentes, coincidentes, exclusivas ${ }^{16}$.

En este orden de ideas el artículo 73 de la Constitución establece que el Congreso tiene facultades para legislar en materia penal para ciertos delitos, sobre todo los que tienen que ver con delincuencia organizada y materia electoral, así como la legislación procesal penal, de justicia alternativa, de ejecución de penas y de justicia para adolescentes a nivel nacional.

Este artículo, en diversas fracciones, contiene un entramado régimen de distribución de competencias entre autoridades en distintos niveles de gobierno a fin de conocer los delitos del fuero común y del federal; así como para expedir leyes que establezcan las bases de coordinación entre la federación, las entidades federativas y los municipios para que establezcan y organicen las instituciones de seguridad pública.

Este complejo sistema de competencias no contribuye a delimitar el papel y las responsabilidades de cada uno de los órdenes de gobierno y sobre todo, de los actores que tienen a su cargo la tarea de la seguridad.

El federalismo mexicano nunca ha sido un modelo de colaboración intergubernamental. Las relaciones entre federación y estados se han movido entre la sujeción y el conflicto, dejando poco espacio para la cooperación y la competencia creativa. Sin embargo, la crisis de seguridad de los últimos cinco años ha exacerbado las contradicciones del arreglo federal mexicano, y detonado un carnaval de acusaciones cruzadas entre gobernadores y funcionarios federales ${ }^{17}$.

Incluso esta falta de delimitación de competencias y distribución de facultades ha dado origen para que se considere constitucional la intervención de las fuerzas armadas en tareas de seguridad $^{18}$.

\section{Principios de actuación y rasgos de las instituciones de seguridad pública}

Instituciones. El noveno párrafo del artículo 21 de la Constitución establece los principios que regirán la actuación de las instituciones de seguridad pública y, en este sentido la Ley General del Sistema Nacional de Seguridad Pública establece que bajo este concepto de instituciones de seguridad pública se comprenden a las instituciones Policiales, de Procuración de Justicia, del Sistema Penitenciario y dependencias encargadas de la Seguridad Pública a nivel federal, local y

\footnotetext{
15 Artículo 124. Las facultades que no están expresamente concedidas por esta Constitución a los funcionarios federales, se entienden reservadas a los Estados o a la Ciudad de México, en los ámbitos de sus respectivas competencias.

16 Tena Ramírez, Felipe (20oo), Derecho constitucional mexicano, México, Porrúa, p. 174.

17 Instituto Mexicano de Competitividad (2012), ¿Dónde quedó la bolita? Del federalismo de la recriminación al federalismo de la eficacia, México, p.54.

${ }^{18}$ Tesis P./J. 39/200o. Semanario Judicial de la Federación y su Gaceta, Novena Época, México, Tomo III, Abril de 2000 , pág. 470.
} 
municipa ${ }^{19}$, los cuales son las autoridades que deberán sujetarse a los principios que se analizan a continuación:

Principios. El Manual para la Evaluación del Desempeño del Personal de las Instituciones de Seguridad Pública define la noción general de principio, así como cada uno de los que integran el conjunto de principios enunciados por la Constitución y la Ley General del Sistema Nacional de Seguridad Pública.

Un principio es en esencia, el enunciado general que da la razón de ser y fundamento a un sistema. Es una idea rectora ${ }^{20}$.

Legalidad. Se debe entender toda aquella intervención o decisión que se encuentra fundada en el Derecho, entendido este último en su más amplio sentido, y que se basa además en la técnica de interpretación jurídica que mayor certeza genere en la solución de los conflictos ${ }^{21}$.

\section{Objetividad}

Consiste en un actuar congruente oportuno y proporcional al hecho con las razones que el derecho le suministran, y no por las que se deriven de su modo personal de pensar o de sentir por lo tanto el servidor de la seguridad pública al actuar no busca reconocimiento alguno. Al tomar sus decisiones en forma individual, colectiva o recibir órdenes, buscará siempre cumplir con su función, frente a cualquier beneficio o ventaja personal y procurará actuar con serenidad de ánimo y equilibrio interno, a fin de que sus decisiones estén desprovistas de aprehensiones y prejuicios ${ }^{22}$.

Eficiencia. Es la virtud de lograr el objetivo de la función de la seguridad pública y de los procedimientos, que no es otro que el responsable del orden, la tranquilidad y seguridad de bienes y personas en una forma real, posible y legal, en condiciones que el propio Derecho determina ${ }^{23}$.

Profesionalismo. Es la respuesta de más alta excelencia y de conocimiento profundo de la teoría, técnica y práctica, que un servidor de la seguridad pública debe externar en su ejercicio laboral, para lo cual deberá siempre actualizarse y capacitarse con objeto de elevar la calidad de las actividades que le corresponde desempeñar ${ }^{24}$.

Honradez. Entendida como la rectitud de ánimo, como la honorabilidad y la integridad en el actuar, sin esperar ni pedir algo que no sea cumplir con la función en los términos que el propio

\footnotetext{
${ }^{19}$ Artículo 5, frac. VIII de la Ley General del Sistema Nacional de Seguridad Pública.

${ }^{20}$ Secretaría de Gobernación (2011), Manual para la Evaluación del Desempeño del Personal de las Instituciones de Seguridad Pública, Secretariado Ejecutivo del Sistema Nacional de Seguridad Pública, México, p 17, [en línea]disponible en: http://secretariadoejecutivosnsp.gob.mx/work/models/SecretariadoEjecutivo/Resource/348/1/ images/MANUAL_EVALUACION_HABILIDADES_DESTREZAS_CONOCIMIENTOS_ANEXO\%2oI.pdf.Manual para la Evaluación del Desempeño del Personal de las Instituciones de Seguridad Pública.

${ }^{21}$ Ídem.

22 Ídem.

${ }^{23}$ Ibídem, p. 18.

${ }^{24}$ Ídem.
} 
Derecho exige. El servidor público no deberá utilizar su cargo público para obtener algún provecho o ventaja personal o a favor de terceros.

Tampoco deberá buscar o aceptar compensaciones o prestaciones de cualquier persona $\mathrm{u}$ organización que puedan comprometer su desempeño como servidor público ${ }^{25}$.

Respeto a los Derechos Humanos. La preservación del estado de derecho, la defensa y protección de la dignidad humana para garantizar los más amplios márgenes posibles para el bien común.

Entre esos derechos destacan las garantías de audiencia y de legalidad, el debido proceso, la debida defensa la no retroactividad de la ley, la presunción de inocencia, la debida fundamentación y motivación, el juicio justo, las instancias del proceso y la prohibición de la tortura entre otros. Aunque todos los derechos humanos tienen una importancia especial, el derecho a la vida es básico y fundamental ${ }^{26}$.

Disciplina $^{27}$. La disciplina comprende el aprecio de sí mismo, la pulcritud, los buenos modales, el rechazo a los vicios, la puntualidad en el servicio, la exactitud en la obediencia, el escrupuloso respeto a las leyes y reglamentos, así como a los derechos humanos. La disciplina es la base del funcionamiento y organización de las Instituciones Policiales, por lo que sus Integrantes deberán sujetar su conducta a la observancia de las leyes, órdenes y jerarquías, así como a la obediencia y al alto concepto del honor, de la justicia y de la ética. La disciplina demanda respeto y consideración mutua entre quien ostente un mando y sus subordinados ${ }^{28}$.

Los principios son las bases que regirán la conducta de los funcionarios encargados de la seguridad pública. Existe una interrelación entre prácticamente todos los principios, pues para colmar el principio de legalidad, el de respeto a los Derechos Humanos y el de profesionalismo, por ejemplo, es necesario capacitar a dichos funcionarios no sólo en cuestiones relativas al orden jurídico mexicano, sino también de tratados internacionales de Derechos Humanos y protocolos de actuación para que estos sean la base de un desempeño eficiente, objetivo, honrado y disciplinado.

Los principios se miden en base a parámetros establecidos en el manual antes mencionado, mismo que ofrece una serie de rúbricas de evaluación en las que se encuentran los criterios con atributo ${ }^{29}$ que se someterán a evaluación, si se estudian con atención dichos criterios, es posible darse cuenta del enorme reto que representa dotar a las instituciones de seguridad pública, en todos los niveles de gobierno, de formación, no sólo de capacitación, porque ésta se refiere a únicamente brindar elementos técnicos que conllevan el saberes declarativos y procedimentales, pero la formación precisa de competencias actitudinales como el saber ser y saber convivir ${ }^{30}$.

Como ya se mencionó, es posible que las autoridades responsables de la seguridad pública conozcan o lleguen a conocer toda la ciencia y la técnica de su labor, pero luego, para poder aplicarla en aras de alcanzar la seguridad será necesario orientar su conducta a valores (lo cual

\footnotetext{
25 Ídem.

26 Ídem.

${ }^{27}$ Ibídem, p.6.

${ }^{28}$ Ibídem, p. 19

${ }^{29}$ Íbidem, pp. 25-31.

${ }^{30}$ El enfoque de la complejidad propone la superación del ideal clásico de racionalidad, centrado en el primado de la razón, la objetividad del saber, el método y la noción del conocimiento puesto al servicio del hombre para el bien. UNESCO and International Bureau of Education Working Papers on Curriculum Issues (2008) $N^{\circ} 8$ Conocimiento complejo y competencias educativas, Suiza, p. 3.
} 
tiene que ver con la honradez, la objetividad, la disciplina, para así ser eficientes, es decir, lograr niveles de seguridad), ello se presenta como un reto enorme que puede ser señalado como uno de los grandes puntales del Sistema Nacional de Seguridad Pública en México, pues debemos recordar que la corrupción es un obstáculo mayúsculo para la consecución de la seguridad. Todo esto significa que habrá que depurar a las instituciones y vigilar el ingreso de elementos que cuenten con las cualidades necesarias para operar como elemento de la seguridad pública. Se requiere de una verdadera carrera de formación en todos los niveles y con todos los funcionarios.

\section{Rasgos de las instituciones}

El décimo párrafo del artículo 21 constitucional establece los rasgos de las instituciones de seguridad pública, los cuales son el carácter civil, el carácter disciplinado y el carácter profesional. A estos dos últimos ya se ha hecho mención líneas arriba a través de los principios, sin embargo cabe hacer una breve reflexión sobre el carácter civil de las instituciones de seguridad pública.

Cuando se habla de carácter se alude al conjunto de cualidades o circunstancias propias de una cosa, de una persona o de una colectividad, que las distingue, por su modo de ser u obrar, de las demás ${ }^{31}$. Entonces, al hablar del carácter civil de la seguridad pública se puede afirmar que se trata de una cualidad propia de la esencia, del ser de la seguridad pública, ésta debe ser civil en dos sentidos:

\section{Propia de las autoridades civiles y por exclusión, no militar}

\section{Puesta al servicio de la sociedad civil y en la que ésta forma parte}

Estas tesis requieren, para ser sustentadas, una gran cantidad de argumentos y análisis que escapan al objeto de este trabajo y que forman parte de otro más extenso, por lo que me limitaré a derivar de los propios preceptos constitucionales tal esencia.

Para la primera tesis, cabe destacar que la Constitución le concede facultades al ejecutivo federal para preservar la seguridad nacional a través del uso de las fuerzas armadas32, conforme a este precepto, la seguridad nacional comprende la seguridad interior y la defensa exterior de la Federación. Por su parte, el artículo 21 de la misma norma señala cuáles debe ser los rasgos de las instituciones de seguridad pública y la Ley de la materia, a la que también ya se hizo alusión, establece qué se entiende por instituciones de seguridad pública ${ }^{33}$, en las que por supuesto no se incluyen a las fuerzas armadas, aunque la Corte ha establecido a través de jurisprudencia la constitucionalidad de la participación de los Secretarios de la Defensa y la Marina, en el Consejo de Seguridad Pública ${ }^{34}$, ello no implica que su intervención sea legítima, pues no hay bases para justificar este ultraje a la democracia bajo un discurso garantista, sólo se explica bajo la razón de Estado, pues lo miembros de las fuerzas armadas no están sometidos a los principios y

\footnotetext{
${ }^{31}$ http://dle.rae.es/?id=7OboGAc

${ }^{2}$ Cfr. Constitución Política de los Estados Unidos Mexicanos, Artículo 89, fracción VI.

${ }^{33}$ Cfr. artículo $5^{\circ}$, fracciones VIII, IX y X de la Ley General del Sistema Nacional de Seguridad Pública.

${ }^{34}$ En 1996 cuando la Suprema Corte de Justicia de la Nación por unanimidad de once votos, mediante la acción de inconstitucionalidad 1/1996 estableció la directriz que permite que los titulares de las Fuerzas Armadas participen en el Consejo de Seguridad Pública y asuman tareas de seguridad pública.
} 
controles a los que las instituciones de seguridad pública sí deben estarlo ni México se encuentra en el supuesto contemplado por el artículo 129 constitucional.

Sin embargo, la reciente Ley de Seguridad Interior ${ }^{35}$ faculta a las Fuerzas Armadas a intervenir en tareas de seguridad pública, por más que se pretenda desvirtuar el sentido y alcance de una supuesta seguridad interior, en realidad lo que se pretende es suplir las deficiencias de las autoridades de seguridad pública, empero, en el pasado esto ya se ha hecho aun sin contar con la normatividad que acaba de publicarse en el Diario Oficial de la Federación y los resultados redundan en más violencia.

Para la segunda tesis sostengo que dentro del propio texto del artículo 21 constitucional, en las bases mínimas se establece la participación de la comunidad como coadyuvante, y menciona: entre otros, en los procesos de evaluación de las políticas de prevención del delito así como de las instituciones de seguridad pública ${ }^{36}$. Dicha coadyuvancia es dentro del Sistema Nacional de Seguridad Pública, y aunque estos procesos se establecen de forma enunciativa y no limitativa, la Ley del Sistema Nacional de Seguridad Pública también prevé dicha participación al establecer su fomento y considerar especial intervención a las instituciones académicas ${ }^{37}$, lo cual implica la apertura de espacios para la sociedad.

Esto responde a un proceso democrático de inclusión, pero también de cambio de paradigma en el que las instituciones que antes se encontraban sólo al servicio del poder político, ahora deben responder ante la sociedad. En este sentido la Organización de Estados Americanos en el Informe sobre Seguridad Ciudadana y Derechos Humanos 2009, propone el concepto de seguridad ciudadana como el más adecuado para el abordaje de los problemas de criminalidad y violencia desde la perspectiva de los derechos humanos, no así los conceptos de seguridad pública, seguridad interior u orden público, pues deriva hacia un enfoque centrado en la construcción de mayores niveles de ciudadanía democrática, con la persona humana como objetivo central de las políticas ${ }^{38}$. Y aunque el concepto no ha cambiado en nuestro texto constitucional, creemos que su contenido debe estar orientado hacia esta visión pues esto es congruente con la reforma constitucional de 2011, la cual obliga al Estado mexicano a reconocer un espectro más amplio de la dimensión de los derechos humanos que se encuentren en tratados internacionales de los cuales sea parte.

Si bien es cierto que la seguridad ciudadana surge de la noción de orden público, su visión compartida de la tarea de gobierno y ciudadanía, además de su propuesta de una política preventiva y no punitiva, hacen que responda con mayor certeza a las problemáticas actuales en materia de seguridad. Se parte entonces de que la seguridad es una tarea compartida y no

\footnotetext{
${ }^{35}$ Ley de Seguridad Interior, Diario Oficial de la Federación del 21 de diciembre de 2017, [en línea] disponible en: http://www.diputados.gob.mx/LeyesBiblio/pdf/LSInt_211217.pdf

${ }^{36}$ Cfr. Artículo 21 Constitucional, inciso d que establece las bases mínimas del Sistema Nacional de Seguridad Pública.

37 También se prevé en el último párrafo del artículo 12 de la Ley General del Sistema Nacional de Seguridad Pública, la participación, por invitación del Consejo de Seguridad Pública a personas, instituciones y representantes de la sociedad civil que puedan exponer conocimientos y experiencias para el cumplimiento de los objetivos de la seguridad pública.

${ }^{38}$ Rodríguez Luna, Ricardo y Martínez Nava, Susana (2016), "De la seguridad pública a la seguridad humana", en: Teresita Rendón Huerta Barrera y Julio César Kala (coords.), Seguridad y políticas públicas, Universidad de Guanajuato- Gobierno del Estado de Guanajuato, México, p. 86.
} 
exclusiva de la policía, sino incluyente, de ciudadanos (en sus diversas formas de organización, como clubes, ligas, ONG y asociaciones civiles) e instituciones gubernamentales ${ }^{39}$.

En este sentido se expresa la fracción II del artículo 20 de la Ley General del Sistema Nacional de Seguridad Pública: el Centro Nacional de Prevención del Delito y Participación Ciudadana tendrá, como principales atribuciones: [...] II. Promover la cultura de la paz, la legalidad, el respeto a los derechos humanos, la participación ciudadana y una vida libre de violencia;

\section{Sistema Nacional de Seguridad Pública}

La última parte del artículo 21 constitucional reitera como base de la seguridad pública, la actuación de las autoridades en los tres niveles de gobierno a través de su coordinación, lo cual les permitirá alcanzar los fines de la seguridad, para ello se crea el Sistema Nacional de Seguridad Pública y se establecen bases mínimas para su funcionamiento. Dichas bases consideran la necesidad de regular la selección, ingreso, formación, permanencia, evaluación, reconocimiento y certificación de los integrantes de las instituciones de seguridad pública; la conformación de bases de datos criminalísticas y de personal de las instituciones; la formulación de políticas públicas; la participación de la sociedad y el destino de los fondos de ayuda federal para las entidades federativas y municipios.

Este sistema estará integrado por el Consejo Nacional de Seguridad Pública, las conferencias nacionales de procuración de justicia, secretarios de seguridad pública o sus equivalentes, sistema penitenciario, seguridad pública municipal, los consejos locales o instancias regionales y el Secretario Ejecutivo del Sistema. A su vez, el Consejo Nacional de Seguridad Pública se compone por el Ejecutivo federal, así como varios secretarios de estado entre los que se encuentran los de la Marina y Defensa Nacional, así como nuevamente, el Secretario Ejecutivo.

Las funciones del Consejo serán articular las acciones de las diferentes dependencias, así como de los diferentes niveles de gobierno para alcanzar los fines de la seguridad pública, también el diseño de políticas públicas, la toma de decisiones estratégicas para la seguridad y muchas otras atribuciones que les permitan cumplir con tal función.

Este marco normativo constituye una gran acumulación de atribuciones y competencias en instancias centralizadoras que tienden a crear una idea ambivalente del modelo de seguridad que pueda funcionar en México pues tiene un fuerte componente punitivo y presta muy poca atención al enfoque preventivo de la seguridad, el cual está más centrado en la sociedad, que en la jerarquía de las instituciones que con un alto grado de complejidad en sus relaciones se encuentran más cercanas a la burocracia que a la eficiencia.

Una [sic] cantidad importante de estados y municipios en México se han generado ciertos desequilibrios internos que requieren ser atendidos en el futuro cercano. Es muy importante tener presente que el desequilibrio no proviene del desarrollo de las funciones de seguridad pública municipal, sino de la falta de esfuerzos de la misma magnitud en el resto de las políticas y programas locales, con excepción de las políticas y programas de combate a la pobreza y algunos rubros contemplados en el Ramo 33 del Presupuesto de Egresos de la Federación.

\footnotetext{
39 Palacios Arzate, José Luis y Sierra Velázquez, José de Jesús (2014), “El concepto de seguridad ciudadana: una perspectiva desde los estudios de la paz", en: Estrada Rodríguez, José Luis (coord.) Seguridad ciudadana: visiones compartidas, Instituto de Administración Pública del Estado de México, A.C.- Universidad Autónoma del Estado de México- Facultad de Ciencias Políticas y Sociales, México, p. 61.
} 
En segundo lugar, y muy relacionado con lo anteriormente dicho, de la misma forma en que el rápido desarrollo de las estructuras de seguridad pública ha generado desequilibrios de tipo organizativo en los gobiernos estatales y de los ayuntamientos, en lo que toca a la comprensión, interpretación, adaptación y aplicación del marco jurídico de la seguridad pública, es posible afirmar que los municipios del país enfrentan serias dificultades para integrar politicas públicas que incorporen y contemplen todas y cada de las normas y previsiones técnicas que conforman dicho marco ${ }^{40}$.

\section{Conclusiones}

La seguridad es un tema que ha cobrado una gran relevancia en las últimas décadas, pero sobre todo en los dos últimos sexenios en los que se ha exacerbado la violencia. Dicha exacerbación de la violencia no sólo corresponde a la delincuencia, sino también a la reacción por parte del Estado para intentar combatirla, sin embargo los resultados no son los deseables, pese a que la norma constitucional presenta múltiples adiciones y reformas que desean perfilar a México como un Estado constitucional de derecho, en el que la democracia impere como forma de vida y permita el desarrollo humano.

En las normas constitucionales parece existir un doble discurso: garantista por un lado y represivo por el otro: mientras hay normas que privilegian la participación ciudadana, hay otras que alejan mucho a las autoridades de la sociedad, mientras que hay normas que nos lanzan a la vanguardia en materia de derechos humanos, hay otras que establecen la inaplicación de compromisos internacionales por el criterio discrecional del ejecutivo, y todavía a esta ambivalencia se le puede agregar la forma en la que se diseñan y ejecutan las políticas públicas, la actuación de los operadores de los sistemas previstos por el Estado, tanto para la procuración e impartición de justicia, como para la seguridad pública; que en esta ocasión no son materia del análisis, pero que a partir de su apreciación podrían hacer lucir más distante una realidad democrática.

\section{Bibliografía}

Cámara de Diputados (2010), "Dictamen de las Comisiones Unidas de Puntos Constitucionales y de Derechos Humanos con proyecto de decreto que modifica la denominación del Capítulo I del Título Primero y reforma artículos 10, 30, 11, 15, 18, 29, 33, 89, 97, 102 y 105 de la Constitución Política de los Estados Unidos Mexicanos”, Diario de los Debates, 15 de diciembre de 2010, Discusión y votación 15 de diciembre de 2010, [en línea] disponible en: $h t t p: / / w w w . d i p u t a d o s . g o b . m x / L e y e s B i b l i o / p r o c e s o / l x i / 117 \_D O F \_10 j u n 11 . p d f$

Constitución Políticas de los Estados Unidos Mexicanos.

Instituto De Investigaciones Jurídicas (1985), Diccionario Jurídico Mexicano, Universidad Nacional Autónoma de México, Tomo IV, México.

Ley de Seguridad Interior (2017), Diario Oficial de la Federación, 21 de diciembre de 2017.

\footnotetext{
40 Sosa López, José de Jesús (2014), "Las políticas de seguridad a nivel estatal y municipal: entre la legalidad y la eficacia”, en: Estrada Rodríguez, José Luis (coord.), Seguridad Ciudadana: visiones compartidas, Instituto de Administración Pública del Estado de México, A.C., Universidad Autónoma del Estado de México y Facultad de Ciencias Políticas y Sociales, p. 127.
} 
Ley General del Sistema Nacional de Seguridad Pública (2009), Diario Oficial de la Federación, 2 de enero de 2009.

García Ramírez, Sergio (2006), “En torno a la seguridad pública. Desarrollo penal y evolución del delito”, en: Derechos Humanos, Órgano Informativo de la Comisión de Derechos Humanos del Estado de México, núm. 78, marzo-abril, pp. 41-50, disponible en: https://revistas-colaboracion.juridicas.unam.mx/index.php/derechos-humanos-emx/ article/view/24505/21959.

González Ruiz, Samuel y otros (1994), Seguridad pública en México: problemas, perspectivas y propuestas, México, Universidad Nacional Autónoma de México.

Instituto Mexicano de Competitividad (2012), ¿Dónde quedó la bolita? Del federalismo de la recriminación al federalismo de la eficacia, México.

Instituto Nacional de Estadística y Geografía (2016), Encuesta Nacional de Victimización y Percepción sobre Seguridad Pública 2016, [en línea] disponible en: http://www.beta. inegi.org.mx/contenidos/proyectos/enchogares/regulares/envipe/2016/doc/envipe2016_presentacion_nacional.pdf.

Organización de las Naciones Unidas (1998), Estatuto de Roma de la Corte Penal Internacional, Roma.

Palacios Arzate, José Luis y Sierra Velázquez, José de Jesús (2014), “El concepto de seguridad ciudadana: una perspectiva desde los estudios de la paz", en: Estrada Rodríguez, José Luis (coord.), Seguridad ciudadana: visiones compartidas, Instituto de Administración Pública del Estado de México, A.C.- Universidad Autónoma del Estado de MéxicoFacultad de Ciencias Políticas y Sociales, México.

Rodríguez Luna, Ricardo y Martínez Nava, Susana (2016), “De la seguridad pública a la seguridad humana”, en: Teresita Rendón Huerta Barrera y Julio César Kala (coords.), Seguridad y políticas públicas, Universidad de Guanajuato- Gobierno del Estado de Guanajuato, México.

Romero Ruiz, Guillermo (2008), “El Distrito Federal: entre la seguridad pública y la seguridad ciudadana”, Crimonogénesis, cuatrimestral, año 1, número 2, febrero.

Secretaría de Gobernación (2011), Manual para la Evaluación del Desempeño del Personal de las Instituciones de Seguridad Pública, Secretariado Ejecutivo del Sistema Nacional de Seguridad Pública, México, [en línea] disponible en: http://secretariadoejecutivosnsp. gob.mx/work/models/SecretariadoEjecutivo/Resource/348/1/images/MANUAL_EVALUACION_HABILIDADES_DESTREZAS_CONOCIMIENTOS_ANEXO\%2oI.pdf.

Secretaría de Servicios Parlamentarios (2008), Exposición de motivos de la iniciativa de reforma diversas disposiciones constitucionales en materia de justicia penal y seguridad pública, México.

Semanario Judicial de la Federación (2000), Gaceta, Novena Época, México, Tomo III, Abril. 
Sosa López, José de Jesús, "Las políticas de seguridad a nivel estatal y municipal: entre la legalidad y la eficacia”, en: Estrada Rodríguez, José Luis (coord.), Seguridad Ciudadana: visiones compartidas, Instituto de Administración Pública del Estado de México, A.C., Universidad Autónoma del Estado de México y Facultad de Ciencias Políticas y Sociales.

Tena Ramírez, Felipe (200o), Derecho constitucional mexicano, México, Porrúa.

UneSCO and International Bureau of Education (200o), Working Papers on Curriculum Issues No 8, Conocimiento complejo y competencias educativas, Suiza. 